\title{
STUDY ON ANTIMICROBIAL RESISTANCE PATTERN IN A TERTIARY CARE HOSPITAL - AN OBSERVATIONAL RETROSPECTIVE STUDY
}

\author{
RANGAPRIYA M*, ALINA LORANCE, ANISHA MERIN VARGHESE, ARSHI HANIF, ARUNA S
}

\author{
Department of Pharmacy Practice, Swamy Vivekanandha College of Pharmacy, Elayampalayam, Namakkal, Tamil Nadu, India.
} Email: priyanarayan97@gmail.com

Received: 15 May 2021, Revised and Accepted: 25 September 2021

\section{ABSTRACT}

Objective: The aim of the study was to monitor the magnitude and trends in antimicrobial resistance through surveillance programs and bacteriological diagnostic methods.

Methods: The study research has performed a retrospective observational study for period of 6 months (Dec 2019-June 2020) to determine the antimicrobial susceptibility pattern on cultures of various specimens at Vivekanandha Medical Care Hospital. The resultant data were computed in Microsoft Excel. Analyses were expressed as the total number, frequencies, and percentage.

Results: A total of 110 culture and sensitivity reports were collected from microbiology departments. Among the culture report, $84 \%$ accounted for gram-negative and $16 \%$ for Gram-positive organisms. Out of eight specimens, 15 different bacteria were identified and the most common bacteria were Klebsiella pneumonia (25\%), E. coli (14\%), Staphylococcus aureus (13\%), and Pseudomonas aeruginosa (12\%).

Conclusion: The interferences from the present study can help in bridging the gap in future educations, training, and adequate decision-making.

Keywords: Antibiotic, Culture, Sensitivity reports, Microbial resistance.

(C) 2021 The Authors. Published by Innovare Academic Sciences Pvt Ltd. This is an open access article under the CC BY license (http://creativecommons.org/ licenses/by/4.0/) DOI: http://dx.doi.org/10.22159/ajpcr.2021v14i11.42046. Journal homepage: https://innovareacademics.in/journals/index.php/ajpcr

\section{INTRODUCTION}

Antibiotics are essential medicines that combat bacterial infections with the aid of disrupting the method essential for bacterial cell growth and proliferation. They represent one of mankind's crucial medical inventions saving millions of lives throughout the years. The first broad-spectrum antibiotic introduced into the world, Penicillin was discovered by Alexander Fleming in 1928. Penicillin has saved and is still saving millions of lives worldwide playing a major role in treating bacterial diseases and in the creation of today's pharmaceutical industry $[1,2]$. On receiving the Nobel Prize on 1945, December 11, Alexander Fleming has warned regarding the abuses of penicillin one may impose on themselves and on others when they are not used appropriately, and with this thoughtless behavior comes the consequence. Adding to the statement, "The time may come when penicillin can be bought by anyone in the shops."

The genetic ability of resistant microbe to exhibit inhibitory action on antibiotics by resistance genes gives rise to the phenomena called antimicrobial resistance (AMR) [3]. AMR is a severe health issue concern with the extreme impact on the global health sector and economy. They are the subsequent results of evolution through natural selection or we can say antibiotic action. A large part of resistant pathogenic organisms in a micro-biosphere is pushed due to human activities, consisting of indiscriminate use and misuse of antibiotics in humans, veterinary medication, and agriculture [4,5]. At the same time, when high concentrations of antibiotics used therapeutically can create an environment for resistant mutants challenging minor and primary infectious.

Many patients are given a non-specific broad-spectrum medicament for an actual or suspected infection which is often not necessary to the given condition. Subsequently, determining the resistance patterns inside the geographical area will assist in choosing and use of the effectiveness of antibiotics.

\section{METHODS}

The current research performed an observational retrospective study for 6 months (December 2019-June 2020) to determine the antimicrobial susceptibility pattern on cultures of various specimens collected over 2 years. Data on the identified micro-organisms and their antimicrobial susceptibility pattern were obtained from the Clinical Microbiology Laboratory of Vivekanandha Medical Care teaching Hospital (VMCH). The data regarding culture and sensitivity (C/S) were isolated from the different specimens such as pus, blood, wound swab, conjunctival, tracheal, pleural fluid, sputum, and urine and were analyzed including out-patients (OP) and in-patients (IP). To eliminate bias in the collection of research data, the $\mathrm{C} / \mathrm{S}$ reports were filtered to retain only the first isolate of the patient. The report was computed in Microsoft Excel and was expressed as proportions and percentages. The research protocol was approved by the Institutional Ethical Committee, with the approval number SVCP/IEC/JAN/2020/02.

\section{RESULTS}

The total 110 culture and sensitivity reports had shown (46.2\%) significant growth of pathogenic organisms exhibiting resistance to either single or multiple antibiotics.

Distribution of bacteria as per Gram-stain

Among the culture reports collected, $84 \%$ were Gram-negative organisms and $16 \%$ accounted for Gram-positive organisms as depicted in Fig. 1.

Distribution of identified bacterial pathogens

The number of isolates obtained was higher from urine culture $(n=45)$, followed by Pus ( $n=23)$, sputum $(n=17)$, tracheal $(n=9)$, and blood $(\mathrm{n}=8)$. In contrast, the least number of isolates was found in wound swab $(n=4)$, ear swab $(n=3)$, and conjunctival $(n=1)$ as represented in Table 1. 
Organisms isolated from various samples were Enterococcus, Enterobacter baumannii, Streptococcus pneumonia, Proteus, Acetobacter, Staphylococcus hominis, Enterobacter kobei, Klebsiella oxytoca, Corynebacterium striatum, Pseudomonas aeruginosa, and Escherichia coli.

Out of eight specimens, fifteen different bacteria were identified, and the most frequently isolated microorganisms were Klebsiella pneumonia $(\mathrm{n}=27)$, E. coli $(\mathrm{n}=15)$, Staphylococcus aureus $(\mathrm{n}=14)$, and Pseudomonas aeruginosa $(\mathrm{n}=13)$ as depicted in Table 1 .

In percentile, Klebsiella pneumonia was the most common organism isolated with 47\%, followed by Escherichia coli (22\%), Pseudomonas aeruginosa (13\%), Acinetobacter baumannii (5\%), and Proteus mirabilis (4\%) in the Gram-negative organisms. Among Gram-positive organisms, Staphylococcus aureus (37\%), Candida tropicalis (25\%), and Enterococcus faecalis (15\%) were frequently isolated.

As shown in Fig. 2, Klebsiella pneumoniae $(\mathrm{n}=17)$ and Escherichia coli $(\mathrm{n}=15)$ were the most frequent bacteria isolated from the urine culture,

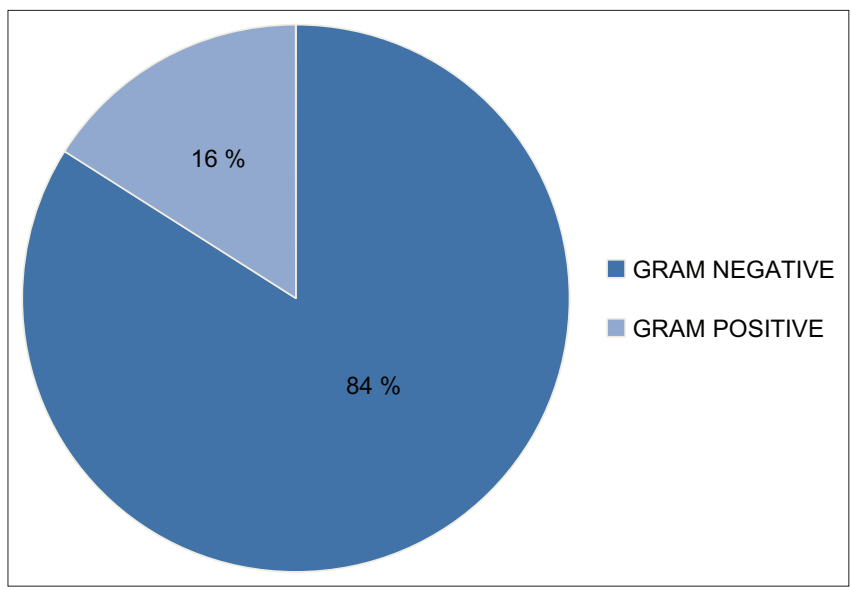

Fig. 1: Distribution of bacteria as per gram stain`
Staphylococcus aureus $(\mathrm{n}=10)$ and Streptococcus pneumoniae $(\mathrm{n}=6)$ were found from pus and Pseudomonas aeruginosa $(\mathrm{n}=5)$ from sputum culture. Staphylococcus aureus $(\mathrm{n}=3)$ was the most seen organism in the blood samples.

Streptococcus pneumoniae $(\mathrm{n}=1)$ was the only organism that was identified in the conjunctival culture test, likewise Corynebacterium striatum $(\mathrm{n}=2)$ in-ear swab. Pseudomonas aeruginosa $(\mathrm{n}=2)$ was majorly seen in wound swab culture. Klebsiella pneumoniae $(\mathrm{n}=2)$, Candida tropicalis $(\mathrm{n}=2)$, and Enterococcus faecalis $(\mathrm{n}=2)$ from tracheal culture test.

\section{Resistant frequency of bacterial isolates}

Among the tested antimicrobials toward Gram-negative and Gram-positive organisms, the study showed more resistance to ampicillin $(\mathrm{n}=36)$ accompanied with co-trimoxazole $(\mathrm{n}=28)$, ceftriaxone $(n=26)$, and cefixime $(n=24)$. The least resistance was shown by tigecycline $(n=6)$, clindamycin $(n=4)$, and cefoperazone $(n=2)$, as represented in Tables 2 and 3.

From seven different pharmacological categories, 37 antimicrobial agents showed resistance towards various organisms. Third-generation cephalosporins (28\%) exhibited superior resistance, followed by penicillin (27\%). Other agents were fluoroquinolones (14\%), oral and parenteral aminoglycosides (5\%), tetracycline (5\%), and macrolides antibiotics $(8 \%)$ along with nitrofurantoin, colistin, rifampin, and co-trimoxazole.

Table 3 depicts the resistance frequency of bacteria toward anti-microbial whereas Table 4 represents the resistance percentile of micro-organisms exhibit towards antibiotics. Escherichia coli have shown 53\% resistance to ciprofloxacin and $47 \%$ resistance to ceftriaxone, co-trimoxazole. Klebsiella pneumoniae showed higher resistance to Ampicillin by $67 \%$. Pseudomonas aeruginosa has shown 33\% resistance to co-trimoxazole, ceftriaxone, cefixime, and levofloxacin. Whereas, Staphylococcus aureus was with the highest resistance to ampicillin at $43 \%$.

\section{DISCUSSION}

The research aimed to study the identified organisms and to understand their antibiotic susceptibility pattern as per the culture and sensitivity

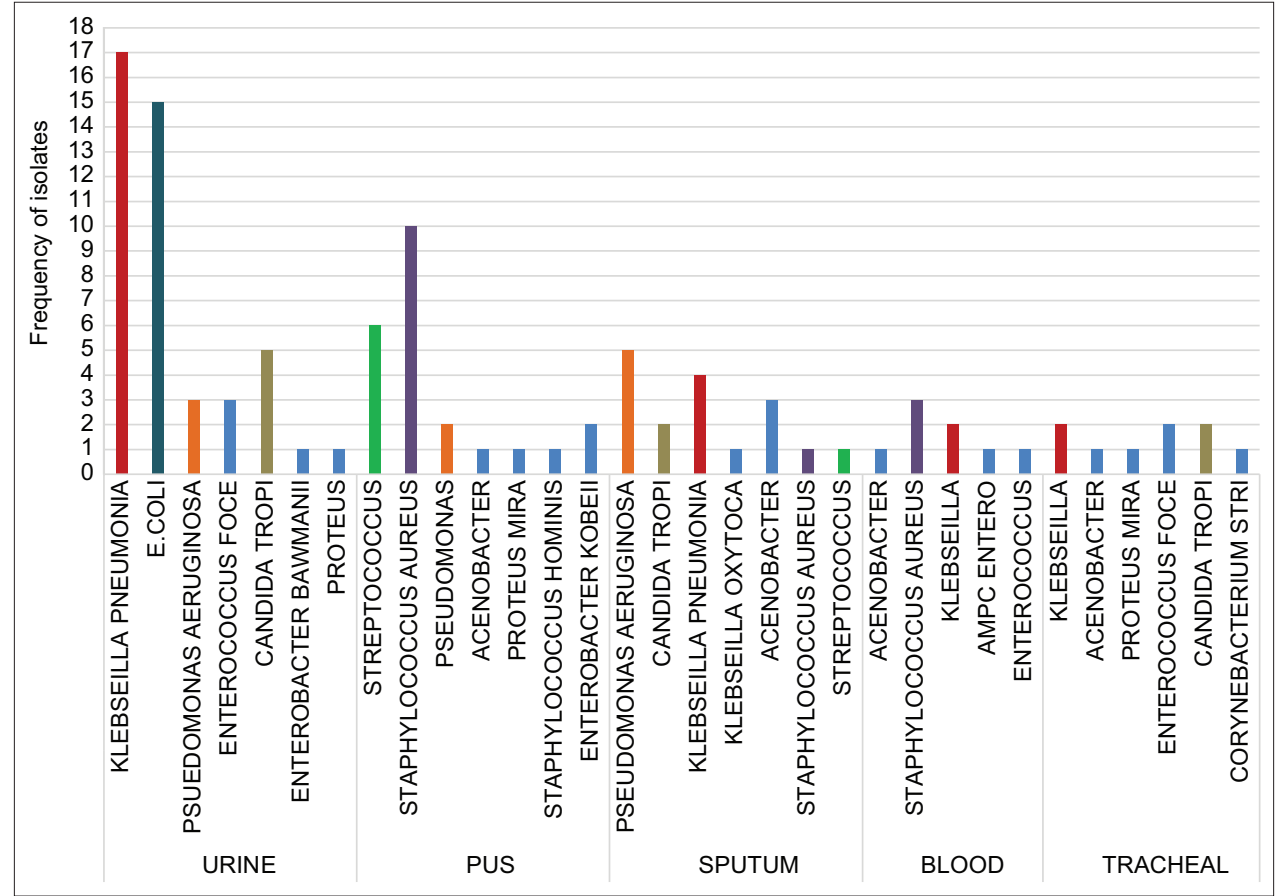

Fig. 2: Organisms in the collected specimens 


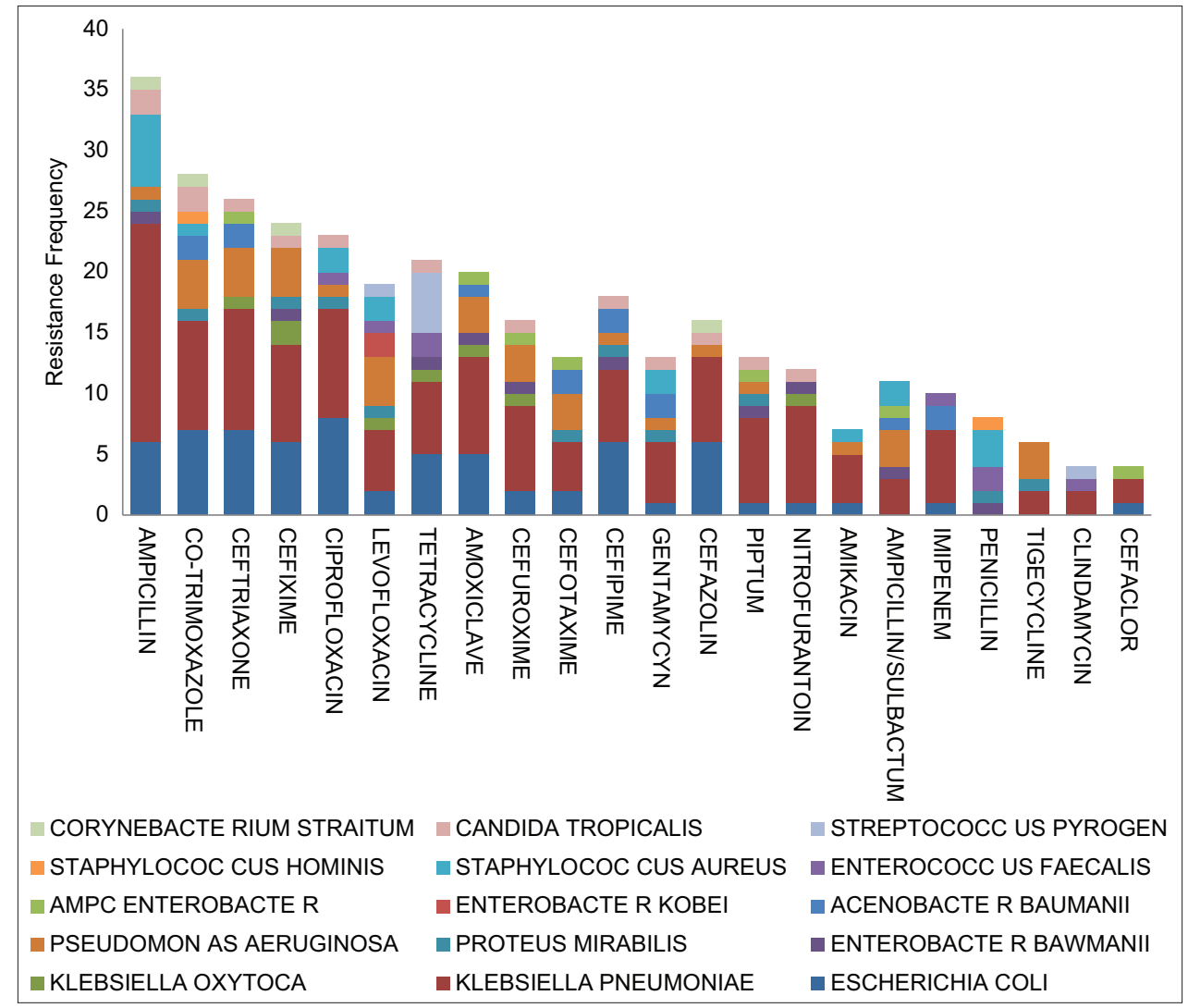

Fig. 3: antibiotic resistance against micro-organism

Table 1: Distribution of identified bacterial pathogens

\begin{tabular}{|c|c|c|c|c|c|c|c|c|}
\hline \multirow[t]{2}{*}{ Type of isolates } & \multicolumn{8}{|c|}{ Type of specimen } \\
\hline & Urine & Pus & Sputum & Blood & Conjunctival & Ear & Wound & Tracheal \\
\hline K. pneumonia & 17 & - & 4 & 2 & - & - & 2 & 2 \\
\hline E. coli & 15 & - & - & - & - & - & - & - \\
\hline P. aeruginosa & 3 & 2 & 5 & - & - & 1 & 2 & - \\
\hline Enterococcus & 3 & - & - & 1 & - & - & - & 2 \\
\hline Candida & 5 & - & 2 & - & - & - & - & 2 \\
\hline E. bawmanii & 1 & - & - & - & - & - & - & - \\
\hline Proteus & 1 & 1 & - & - & - & - & - & 1 \\
\hline Streptococсиs pneuтопіа & - & 6 & 1 & - & 1 & - & - & - \\
\hline S. aureus & - & 10 & 1 & 3 & - & - & - & - \\
\hline Acetobacter & - & 1 & 3 & 1 & - & - & - & 1 \\
\hline S. hominis & - & 1 & - & - & - & - & - & - \\
\hline Enterobacter kobei & - & 2 & - & - & - & - & - & - \\
\hline Klebsiella oxtoca & - & - & 1 & - & - & - & - & - \\
\hline Ampc enterobacter & - & - & - & 1 & - & - & - & - \\
\hline Cornebacteriumstriatus & - & - & - & - & - & 2 & - & 1 \\
\hline
\end{tabular}

(C/S) reports collected from the clinical microbiological laboratory of VMCH. As per the results obtained, Gram-negative organisms (GNO) had the highest predominance accounting for $84 \%$ of total C/S collection, and Gram-positive organisms (GPO) with $16 \%$. The predominance of GNO in hospital settings is similarly seen in other studies of Mehdinejad et al., Ali Shamshad et al., and Melkamu et al. [6-9]. In contrast, other studies had reported GPO as the predominant pathogen in studies conducted by Kalpesh et al., Gupta, and Karlowsky et al. [10-12]. According to studies conducted by Tiwari et al. and Mathai et al. the highest rates of Gram-negative bacillary resistance was found in India and it is well-known that GNO is more frequently encountered in different clinical specimens causing nosocomial infections (sepsis, pneumonia, and meningitis) $[13,14]$.
The predominant Genus/Species in Gram-Negative isolates are Klebsiella (25\%), E. coli (14\%), and Pseudomonas species (12\%). Karlowsky et al., Kalpesh et al., Gupta et al., and Kamga et al. have reported a high incidence of Klebsiella and E. coli. [10-12]. Likewise, in Gram-positive organisms, Staphylococcus aureus (13\%) has shown the highest frequency. This report was consistent with the study of Bhatia et al., Tiwari et al., Kalpesh et al., and Karlowsky et al. where the isolation of the organism was reported $[10,12,51,52]$.

As per the finding, the maximum clinical isolates obtained were from urine specimens (45) followed by pus (23), sputum (17), and tracheal (9). The result was comparable with the reports of Alnamnakani et al. [15]. 
Table 2: Resistant frequency of gram-negative bacterial isolates

\begin{tabular}{|c|c|c|c|c|c|c|c|c|}
\hline Organism & Ampicillin & Co-trimoxazole & Ceftriaxone & Cefixime & Ciprofloxacin & Levofloxacin & Tetracycline & Amoxiclav \\
\hline \multicolumn{9}{|l|}{ GNO } \\
\hline E. coli & 6 & 7 & 7 & 6 & 8 & 2 & 5 & 5 \\
\hline K. pneumoniae & 18 & 9 & 10 & 8 & 9 & 5 & 6 & 8 \\
\hline Klebsiella oxytoca & 0 & 0 & 1 & 2 & 0 & 1 & 1 & 1 \\
\hline $\begin{array}{l}\text { Enterobacte } R \\
\text { bawmanii }\end{array}$ & 1 & 0 & 0 & 1 & 0 & 0 & 1 & 1 \\
\hline Proteus mirabilis & 1 & 1 & 0 & 1 & 1 & 1 & 0 & 0 \\
\hline $\begin{array}{l}\text { Pseudomonas } \\
\text { aeruginosa }\end{array}$ & 1 & 4 & 4 & 4 & 1 & 4 & 0 & 3 \\
\hline Acenobacterbaumanii & 0 & 2 & 2 & 0 & 0 & 0 & 0 & 1 \\
\hline Enterobacter kobei & 0 & 0 & 0 & 0 & 0 & 2 & 0 & 0 \\
\hline Ampcenterobacter & 0 & 0 & 1 & 0 & 0 & 0 & 0 & 1 \\
\hline Organism & Cefuroxime & Cefotaxime & Cefipime & Gentamycyn & Cefazolin & Piptum & Nitrofurantoin & Amikacin \\
\hline \multicolumn{9}{|l|}{ GNO } \\
\hline E. coli & 2 & 2 & 6 & 1 & 6 & 1 & 1 & 1 \\
\hline K. pneumoniae & 7 & 4 & 6 & 5 & 7 & 7 & 8 & 4 \\
\hline Klebsiella oxytoca & 1 & 0 & 0 & 0 & 0 & 0 & 1 & 0 \\
\hline $\begin{array}{l}\text { Enterobacte R } \\
\text { bawmanii }\end{array}$ & 1 & 0 & 1 & 0 & 0 & 1 & 1 & 0 \\
\hline Proteus mirabilis & 0 & 1 & 1 & 1 & 0 & 1 & 0 & 0 \\
\hline $\begin{array}{l}\text { Pseudomonas } \\
\text { aeruginosa }\end{array}$ & 3 & 3 & 1 & 1 & 1 & 1 & 0 & 1 \\
\hline Acenobacterbaumanii & 0 & 2 & 2 & 2 & 0 & 0 & 0 & 0 \\
\hline Enterobacter kobei & 0 & 0 & 0 & 0 & 0 & 0 & 0 & 0 \\
\hline Ampcenterobacter & 1 & 1 & 0 & 0 & 0 & 1 & 0 & 0 \\
\hline Organism & $\begin{array}{l}\text { Ampicillin/ } \\
\text { sulbactum }\end{array}$ & Penicillin & Tigecycline & Clindamycin & Cefaclor & $\begin{array}{l}\text { Nalidixic } \\
\text { acid }\end{array}$ & Norfloxacin & \\
\hline \multicolumn{9}{|l|}{ GNO } \\
\hline E. coli & 0 & 0 & 0 & 0 & 1 & 1 & 1 & \\
\hline K. pneumoniae & 3 & 0 & 2 & 2 & 2 & 2 & 2 & \\
\hline Klebsiella oxytoca & 0 & 0 & 0 & 0 & 0 & 0 & 0 & \\
\hline $\begin{array}{l}\text { Enterobacte } R \\
\text { bawmanii }\end{array}$ & 1 & 1 & 0 & 0 & 0 & 0 & 0 & \\
\hline Proteus mirabilis & 0 & 1 & 1 & 0 & 0 & 0 & 0 & \\
\hline $\begin{array}{l}\text { Pseudomonas } \\
\text { aeruginosa }\end{array}$ & 3 & 0 & 3 & 0 & 0 & 0 & 0 & \\
\hline Acenobacterbaumanii & 1 & 0 & 0 & 0 & 0 & 0 & 0 & \\
\hline Enterobacter kobei & 0 & 0 & 0 & 0 & 0 & 0 & 0 & \\
\hline Ampcenterobacter & 1 & 0 & 0 & 0 & 1 & 0 & 0 & \\
\hline
\end{tabular}

K. pneumoniae was found to be the major isolate from urine samples and identified etiologic agent following E. coli which was similar to the findings of Alnamnakani et al., Bajaj et al., Sheth et al., Javeed et al., Beyene et al., Tadesse et al., and Mukhtar et al., other studies conducted globally [15,16-21]

Amongst the pus culture samples, Streptococcus pneumonia and Staphylococcus aureus were the most common bacterial agents. Similarly, studies conducted by Alnamnakani et al. and Tiwari et al. have reported Staphylococcus aureus as the most common organism $[13,15]$. Staphylococcus aureus was the most frequently isolated microbe in the blood samples collected during the study period. The findings from previous studies on Ventricular Associated Pneumonia (VAP), Surgical Site Infections (SSI) associated patients, and pediatric populations are in agreement with the above data, that is, E. coli, K. pneumoniae, and Staphylococcus aureus were the major pathogenic organisms. Beyene et al., Tadesse et al., Rao et al., Sandeep et al., Seni et al., Lubega et al., Abebe et al., and Alnamnakani et al. [9,15,19,20,25-28]. These reports support the current findings that these organisms are known etiologies for both community and nosocomial associated infections.

Thehighest percentage of resistance in Escherichia coli causing infections were found to be co-trimoxazole $(47 \%)$, ceftriaxone $(47 \%)$, cefixime (40\%), ampicillin (40\%), cefotaxime (40\%), and cefazolin (40\%) in the sample population. The finding analysis of the current study showed $1^{\text {st }}, 3^{\text {rd }}$, and $4^{\text {th }}$ generation cephalosporin has shown less sensitive compared to the $2^{\text {nd }}$ generation cephalosporin. The study findings were in line with other reports in Ethiopia and overseas. ${ }^{(40-43)}$ Antibiotics that have retained their usefulness and showed the least resistance to the Gram-negative isolate; E. coli were gentamycin, piptum, imipenem, and nitrofurantoin at $93 \%$ and Amikacin at $83 \%$. Comparable data were found in the Divyashanthi et al. study [37]. Apart from cephalosporin, ciprofloxacin has shown a higher resistance percentile of $53 \%$ followed by co-trimoxazole $(47 \%)$, and nalidixic acid $(27 \%)$ in our study. This pattern of resistance was shown by studies conducted by Deep et al., Maksum et al., Barai et al., and other researches [37-42].

Klebsiella sp. showed the highest level of resistance to Ampicillin (67\%). The resistance shown by Klebsiella was also observed in other studies conducted by Sheth et al., Javeed et al., and Divyashanthi et al. [17,18,37]. Likewise, the sensitivity pattern was seen highest at $93 \%$ to norfloxacin, nalidixic acid, cefaclor, clindamycin, and tigecycline followed by gentamycin (82\%), ceftriaxone $(68 \%)$, co-trimoxazole, and ciprofloxacin at $67 \%$ similarly cefixime and nitrofurantoin at $70 \%$. The sensitivity pattern observed was much higher than the studies conducted globally in Gondar, and Ethiopia $[9,44]$.

Findings of the current study showed Klebsiella pneumonia had the highest susceptibility rate for levofloxacin (82\%), cefotaxime (85\%), gentamycin (82\%), amikacin (85\%), ampicillin/sulbactam (89\%), 


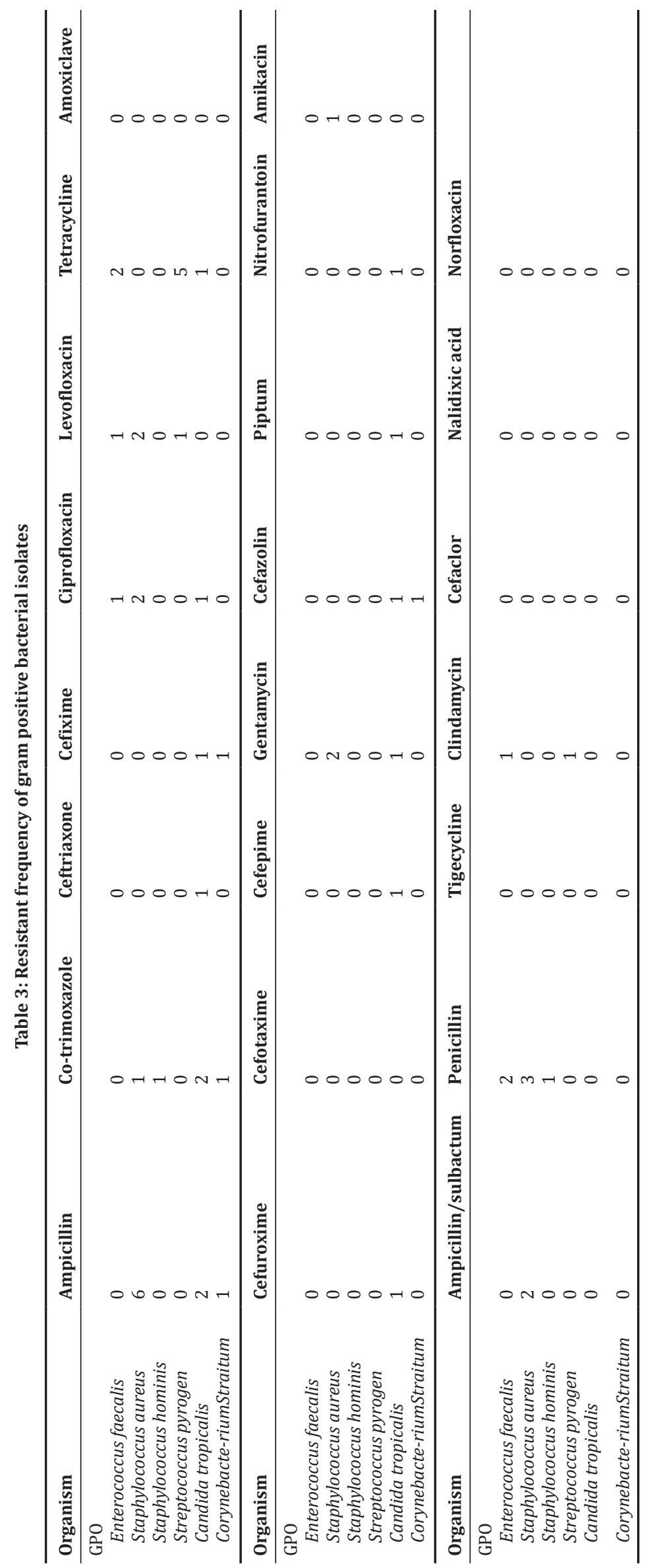


Table 4: Resistance percentile of bacteria

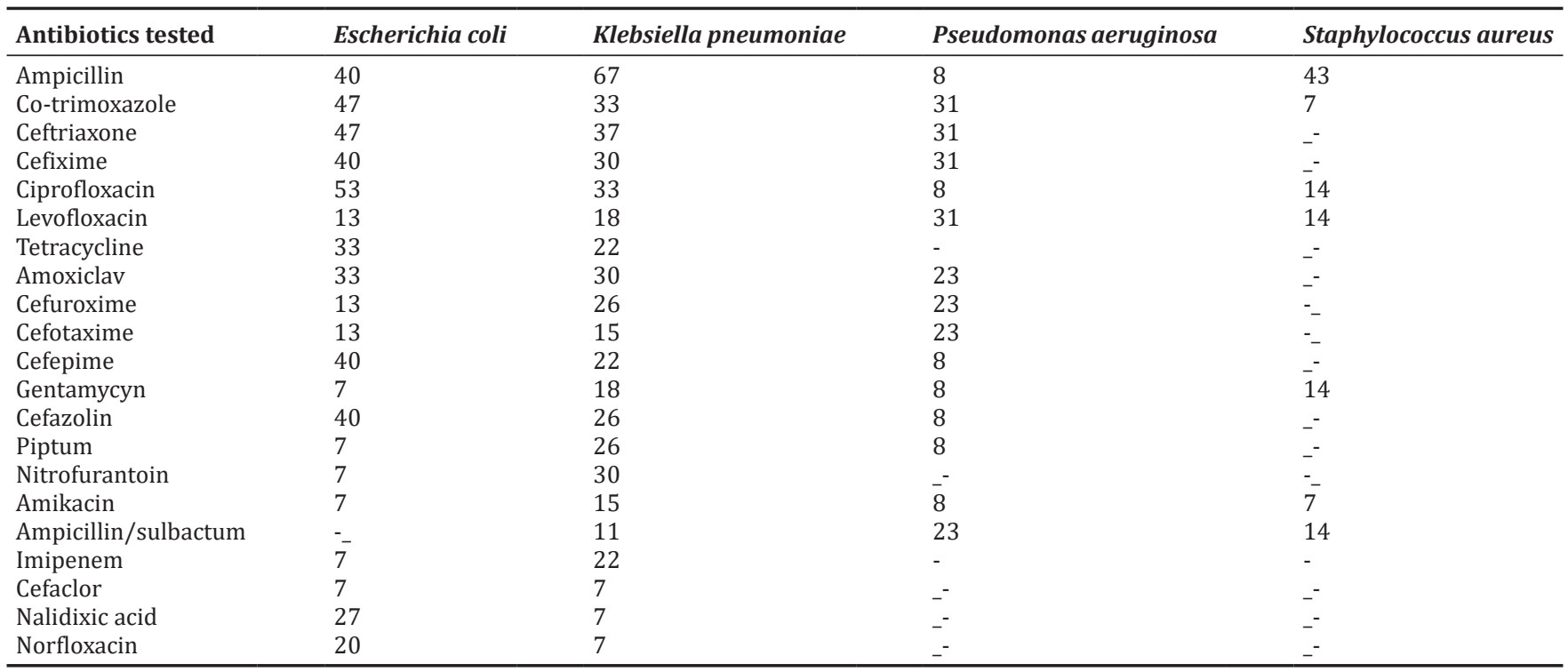

tigecycline, clindamycin, cefaclor, nalidixic acid, and norfloxacin at 93\%. The above finding was relatively higher as compared to other reports done in Ethiopia and Gondar $[9,44]$. Whereas, moderate susceptibility was shown by cefexime (70\%), tetracycline (78\%), amoxyclav $(70 \%)$, cefuroxime $(74 \%)$, cefepime $(78 \%)$, cefazolin $(74 \%)$, piptum $(74 \%)$, and carbapenem (74-78\%). The least sensitivity was observed for ceftriaxone (63\%), co-trimoxazole (67\%), and ciprofloxacin (67\%).

About $22 \%$ of total 14 showed moderate sensitivity towards penicillin antibiotic. In addition, $86 \%$ of isolates have shown higher susceptibility to fluoroquinolones, gentamycin, and ampicillin/sulbactam. The highest sensitivity percentile was observed for amikacin and co-trimoxazole at $93 \%$

Among the Pseudomonas aeruginosa isolates in the current study, aminoglycosides (92\%), and ciprofloxacin (92\%) showed the higher sensitivity. The above result data were in line with Divyashanthi et al., Nyambura et al., Sheth et al., and BasantiPathi et al. $[17,22,37,48]$. Likewise, moderate sensitivity pattern were shown by co-trimoxazole (69\%), ceftriaxone (69\%), levofloxacin $(69 \%)$, cefuroxime (77\%), cefotaxime (77\%), and ampicillin/sulbactam (77\%). The previous other studies conducted in Ethiopia and overseas had also conducted C/S reports on Pseudomonas sp. [33-36].

Antibiotics that had retained their usefulness and showed greater susceptibility pattern to these Gram-negative isolates in the study were amikacin (83\%/85\%/92\%), gentamicin (93\%/82\%/92\%), levofloxacin (87\%/82\%/69\%), piptum (93\%/74\%/92\%), cefaclor (93\%/93\%/92\%) against E. coli, Klebsiella, and Pseudomonas, respectively. This was similar to the previous study reports $[17,18,37,46,47]$

\section{CONCLUSION}

The study was able to observe and provide an epidemiological variation in resistance and sensitivity pattern by comparing the previous reports. To decrease the rising antibiotic resistance, rational use of antibiotics is essential according to the antibiotic resistance pattern of that particular institution. For this concern, a regular epidemiological study needs to be conducted on $\mathrm{C} / \mathrm{S}$ isolates to guide the clinicians in the selection of the appropriate empirical therapy and switching over to the best therapeutic choice based on the data. In addition, study data can be used as a baseline for future analysis to establish prescribing guidelines, determining new therapies, and improve the focus of education and campaigns in reducing AMR.

\section{CONFLICTS OF INTERESTS}

Nil.

\section{AUTHORS FUNDING}

Nil.

\section{REFERENCES}

1. Tan SY, Tatsumura Y. Alexander Fleming (1881-1955): Discoverer of penicillin. Singapore Med J 2015;56:366-7.

2. Science History Institute. Alexander Fleming; 2017. Available from: https://www.sciencehistory.org/historical-profile/alexander-fleming [Last accessed on 2020 Apr].

3. Blair JM, Webber MA, Baylay AJ, Ogbolu DO, Piddock LJ. Molecular mechanisms of antibiotic resistance. Nat Rev Microbiol 2015;13:42-51.

4. Fymat AL. Antibiotics and antibiotic resistance. Biomed J Sci Tech Res 2017; $1: 65-80$

5. Addis M. A review on antibiotic resistant and implication on food chain. Food Sci Qual Manag 2015;42:29-40. Available from: https:// www.iiste.org/journals/index.php/fsqm/article/view/24740

6. Global Action Plan on Antimicrobial Resistance; Available from: https://www.who.int/publications/i/item/9789241509763

7. Mehdinejad M, Khosravi AD, Morvaridi A. Study of prevalence and antimicrobial susceptibility pattern of bacteria isolated from blood cultures. J Biol Sci 2009;9:249-53.

8. Ali S, Waheed K, Iqbal ZH. J Ayub Med Coll Abbottabad 2015;27:117-9.

9. Abebe M, Tadesse S, Meseret G, Derbie A. Type of bacterial isolates and antimicrobial resistance profile from different clinical samples at a referral Hospital, Northwest Ethiopia: Five year data analysis. BMC Res Notes 2019;12:568.

10. Gohel K, Jojera A, Soni S, Gang S, Sabnis R, Desai M. Bacteriological profile and drug resistance patterns of blood culture isolates in a tertiary care nephrourology teaching institute. Biomed Res Int 2014;2014:153747.

11. Gupta CV. Bacteriological profile and antimicrobial susceptibility pattern of blood isolate from a tertiary care hospital in North India. Int J Pharm Res Biosci 2013;2:24-35.

12. Karlowsky A, Jones ME, Draghi DC, Thornsberry C, Sahm DF, Volturo GA. Prevalence and antimicrobial susceptibilities of bacteria isolated from blood cultures of hospitalized patients in the United States in 2002. Ann Clin Microbiol Antimicrob 2004;3:7.

13. Tiwari VB, Kuril BM, Doibale MK. Study of microbiological surveillance data and antibiotic sensitivity patterns for isolates collected at a single tertiary hospital. Int J Recent Trends Sci Technol 2013;7:91-9.

14. Mathai D, Rhomberg PR, Biedenbach DJ, Jones RN, India Antimicrobial Resistance Study Group. Evaluation of the in vitro activity of six broad- 
spectrum beta-lactam antimicrobial agents tested against recent clinical isolates from India: A survey of ten medical center laboratories. Diagn Microbiol Infect Dis 2002;44:367-77

15. Alnamnakani B, Bosso JA. A combination antibiogram to guide empiric therapy for Pseudomonas aeruginosa infections. Year-to-year variation and influence of day of hospitalization isolation. J Clin Lab Med 2016;1:

16. Bajaj JK, Karyakarte RP, Kulkarni JD, Deshmukh AB. Changinga etiology of urinary tract infections and emergence of drug resistance as a major problem. J Commun Dis 1999;31:181-4.

17. Sheth KV, Patel TK. Antibiotic sensitivity pattern of bacterial isolates from the ICU of a tertiary care hospital in India. Trop J Pharm Res 2012;11:991

18. Javeed I, Hafeezamd MR, Anwar S. Antibiotic susceptibility pattern of bacterial isolates from patients admitted to a tertiary care hospital in Lahore. Biomed 2011;27:19-23.

19. Beyene G, Tsegaye W. Bacterial uropathogens in urinary tract infection and antibiotic susceptibility pattern in Jimma University specialized hospital, Southwest Ethiopia. Ethiop J Health Sci 2011;21:141-6.

20. Tadesse S, Kahsay T, Adhanom G, Kahsu G, Legese H, Derbie A. Prevalence, antimicrobial susceptibility profile and predictors of asymptomatic bacteriuria among pregnant women in Adigrat General Hospital, Northern Ethiopia. BMC Res Notes 2018;11:740.

21. Mukhtar AM, Saeed HA. Profile of antibiotic sensitivity and resistance of some pathogenic bacteria isolated from clinical specimens in Sudan. J Sci Technol 2011;12:14-9.

22. Morem N, Claus H, Mshana SE. Antimicrobial resistance pattern: A report of microbiological cultures at a tertiary hospital in Tanzania. BMC Infect Dis 2016;16:1-7.

23. Kayange N, Kamugisha E, Mwizamholya DL, Jeremiah S, Mshana SE. Predictors of positive blood culture and deaths among neonates with suspected neonatal sepsis in a tertiary hospital, Mwanza-Tanzania. BMC Pediatr 2010;10:39.

24. Moremi N, Mushi MF, Fidelis M, Chalya P, Mirambo M, Mshana SE. The predominance of multi-resistant gram-negative bacteria colonizing chronic lower limb ulcers (CLLUs) at Bugando medical center. BMC Res Notes 2014;7:211.

25. Rao R, Sumathi S, Anuradha K, Venkatesh D, Krishna S. Bacteriology of postoperative wound infections. Int J Pharm Biomed Res 2013;4:72-6.

26. Kokate SB, Rahangdale V, Katkar VJ. Study of bacteriological profile of post-operative wound infections in surgical wards in a tertiary care hospital. Int J Contemp Med Res 2017:4:232-5.

27. Seni J, Najjuka CF, Kateete DP, Makobore P, Joloba ML, Kajumbula H, et al. Antimicrobial resistance in hospitalized surgical patients: A silently emerging public health concern in Uganda. BMC Res Notes 2013;6:1-7.

28. Lubega A, Joel B, Lucy NJ. Incidence and etiology of surgical site infections among emergency postoperative patients in Mbarara regional referral hospital, South Western Uganda. Surg Res Pract 2017;2017:6365172.

29. Manyahi J, Matee MI, Majigo M, Moyo S, Mshana SE, Lyamuya EF. Predominance of multi-drug resistant bacterial pathogens causing surgical site infections in Muhimbili National Hospital, Tanzania. BMC Res Notes 2014;7:500

30. Hope D, Ampaire L, Oyet C, Muwanguzi E, Twizerimana H, Apecu RO. Antimicrobial resistance in pathogenic aerobic bacteria causing surgical site infections in Mbarara regional referral hospital, Southwestern Uganda. Sci Rep 2019;9:17299.

31. Mhada TV, Fredrick F, Matee MI, Massawe A. Neonatal sepsis at Muhimbili National Hospital, Dar es Salaam, Tanzania; etiology, antimicrobial sensitivity pattern and clinical outcome. BMC Public Health 2012;12:904.

32. Kayange N, Kamugisha E, Mwizamholya DL, Jeremiah S, Mshana SE. Predictors of positive blood culture and deaths among neonates with suspected neonatal sepsis in a tertiary hospital, Mwanza-Tanzania.
BMC Pediatr 2010;10:39.

33. Beyene G, Tsegaye W. Bacterial uropathogens in urinary tract infection and antibiotic susceptibility pattern in Jimma University Specialized hospital, Southwest Ethiopia. Ethiop J Health Sci 2011;21:141-6.

34. Mukhtar AM, Saeed HA. Profile of antibiotic sensitivity and resistance of some pathogenic bacteria isolated from clinical specimens in Sudan. J Sci Technol 2011;12:14-9.

35. Dagnew M, Yismaw G, Gizachew M, Gadisa A, Abebe T, Tadesse T, et al. Bacterial profile and antimicrobial susceptibility pattern in septicemia suspected patients attending Gondar University Hospital, Northwest Ethiopia. BMC Res Notes 2013;6:283

36. Kibret M, Abera B. Antimicrobial susceptibility patterns of $E$. coli from clinical sources in Northeast Ethiopia. Afr Health Sci 2011;11:40-5.

37. Divyashanthi CM, Adithiyakumar S, Bharathi N. Study of prevalence and antimicrobial susceptibility pattern of bacterial isolates in a tertiary care hospital. Int J Pharm Pharm Sci 2014;7:185-90.

38. Wikipedia. Antibiotic Resistance. United States: Wikimedia Foundation Inc.; Available from: http://www.en.wikipedia.org/wiki/antibiotic_resistance

39. Deep A, Ghildiyal R, Kandian S, Shinkre N. Clinical and microbiological profile of nosocomial infections in the pediatric intensive care unit (PICU). Indian Pediatr 2004;14:1238-46.

40. Maksum R, Siti F, Aribinuko N. Antibiotic sensitivity pattern of bacterial pathogens in the intensive care unit of Fatmawati Hospital, Indonesia. Asian Pac J Trop Biomed 2011;1:39-42.

41. Wikipedia. Antibacterial. United States: Wikimedia Foundation Inc.; 2012. Available from: http://www.en.wikipedia.org/wiki/antibacterial

42. Barai L, Fatema K, Ashraful Haq J, Omar Faruq M, Areef Ahsan AS, Golam Morshed MA, et al. Bacterial profile and their antimicrobial resistance pattern in an intensive care unit of a tertiary care hospital in Dhaka. Ibrahim Med Coll J 2010;4:66-9. Available from: http://www. banglajol.info/index.php/imcj/article/view/6499

43. Hsu LY, Tan TY, Jureen R, Koh TH, Krishnan P, Tzer-Pin Lin R, et al. Antimicrobial drug resistance in Singapore hospitals. Emerg Infect Dis 2007;13:1944-7.

44. Dagnew M, Yismaw G, Gizachew M, Gadisa A, Abebe T, Tadesse T, et al. Bacterial profile and antimicrobial susceptibility pattern in septicemia suspected patients attending Gondar University Hospital, Northwest Ethiopia. BMC Res Notes 2013;6:283.

45. Ansari M, Shah SV, Sen A, Shekh S, Singh GK, Parajuli KP. A retrospective analysis of culture sensitivity and antimicrobial prescribing pattern in a teaching hospital of Eastern Nepal. Natl J Lab Med 2012;1:29-33

46. Bengalorkar GM, Kumar TN. Culture and sensitivity pattern of micro-organism isolated from diabetic foot infections in a tertiary care hospital. Int J Curr Biomed Pharm Res 2011;1:34-40

47. Nathisuwan S, Burgess DS, Lewis JS. Extended-spectrum $\beta$-lactamases: Epidemiology, detection, and treatment. Pharmacother 2001;21:920-8.

48. Pathi B, Mishra SN, Panigrahi K, Poddar N, Lenka PR, Mallick B, et al. Prevalence and antibiogram pattern of Pseudomonas aeruginosa in a tertiary care hospital from Odisha, India. Transworld Med J 2014; $1: 77-80$

49. Kleina EY, van Boeckeld TP, Martineza EM, Panta S, Gandraa S, Levine SA, et al. Global increase and geographic convergence in antibiotic consumption between 2000 and 2015. Proc Natl Acad Sci USA 2018;115:E3463-70.

50. Parthasarathi G. A Textbook of Clinical Pharmacy Practice. $1^{\text {st }}$ ed. New Delhi: Orient Blackswan Private Limited; 2005. p. 72.

51. Tiwari DK, Golia S, Sangeetha KT, Vasudha CL. A study on the bacteriological profile and antibiogram of bacteremia in children below 10 years in a tertiary care hospital in Bangalore. J Clin Diagn Res 2013; 7:2732-5.

52. Bhatia A, Kalra J, Kohli S, Kakati B, Kaushik R. Antibiotic resistance pattern in intensive care unit of a tertiary care teaching hospital. Int $\mathrm{J}$ Basic Clin Pharmacol 2018;7:906-11 